\title{
miR-18a as a potential regulator of estrogen- related genes in human breast carcinomas
}

\author{
Renata C Bueno ${ }^{1 *}$, Fabíola E Rosa ${ }^{2}$, Francisco A Moraes-Neto ${ }^{3}$, José Roberto F Caldeira ${ }^{4}$, Sandra A Drigo ${ }^{5}$, \\ Silvia R Rogatto ${ }^{5}$ \\ From São Paulo Advanced School of Comparative Oncology \\ Águas de São Pedro, Brazil. 30 September - 6 October 2012
}

\section{Background}

Estrogen receptor (ER) status has been used as a biomarker in breast carcinomas (BC), allowing the identification of tumors that may respond to ER antagonists or aromatase inhibitors. Two previous studies by our group evaluating gene and miRNA expression profiles in BC samples from Brazilian patients revealed 15 genes and 3 microRNAs as significantly associated with $\mathrm{BC}$, according to ER status. The aim of this study was to evaluate the correlation between these 3 microRNAs and ER-related genes in $\mathrm{BC}$.

\section{Materials and methods}

miRDIP algorithm was applied to select candidates among 15 ER-related genes for transcriptional regulation by hsa-miR-26a, hsa-miR-26b and miR-18a. Correlation analyses were performed between transcript levels ofERRB4, TMEM205, SUSD3, DNAJC12, RERG, SCN7A, TBC1D9, TCEA3, THSD4, TIGD6 and miRNAs (miR26a, miR-26b, and miR-18a) in BC compared with normal breast samples. miRNA expression was assessed in $63 \mathrm{BC}$ and 5 normal breast samples by quantitative RTPCR using as internal reference RNU48, RNU44 and U47.

\section{Results}

Down-expression of miR-18a was significantly associated with ER-positive tumors $(P=0.005)$, while down-expression of miR-26a and miR-26b were significantly associated with ER-negative tumors $(P=0.006$ and $P=0.003$, respectively). Additionally, a significant negative correlation was detected between overexpression of ERBB4 and
TMEM205 and underexpression of $\operatorname{miR}-18 \mathrm{a}(P<0.001$; $\mathrm{r}=-0.703$ and $P<0.001 ; \mathrm{r}=-0.746$, respectively).

\section{Conclusions}

Our preliminary results suggest thatin ER-positive tumors, over-expression of ERBB4 (receptor tyrosine kinase) and TMEM205 (encoding a hypothetical protein associated with cisplatin resistance) genes could be explained by miR-18a down-expression. Functional studies are being conducted to confirm these findings. This study may contribute for the identification of potential therapeutic agents in $\mathrm{BC}$.

\section{Financial support}

CAPES and CNPq.

\begin{abstract}
Author details
'Department of Genetics, São Paulo State University, Botucatu, SP, Brazil. ${ }^{2}$ Department of Pathology, São Paulo State University, Botucatu, SP, Brazil. ${ }^{3}$ Department of Pathology, Amaral Carvalho Hospital, Jaú, SP, Brazil. ${ }^{4}$ Department of Senology, Amaral Carvalho Hospital, Jaú, SP, Brazil. ${ }^{5}$ NeoGene Laboratory, Department of Urology, São Paulo State University, Botucatu, SP, Brazil and A. C. Camargo Cancer Treatment and Research Center, São Paulo, SP, Brazil.
\end{abstract}

Published: 4 April 2013

doi:10.1186/1753-6561-7-S2-P59

Cite this article as: Bueno et al:: miR-18a as a potential regulator of estrogen-related genes in human breast carcinomas. BMC Proceedings 2013 7(Suppl 2):P59.

* Correspondence: recbueno@gmail.com

'Department of Genetics, São Paulo State University, Botucatu, SP, Brazil

Full list of author information is available at the end of the article

(C) 2013 Bueno et al; licensee BioMed Central Ltd. This is an Open Access article distributed under the terms of the Creative Commons 